\title{
Effects of thermal intermittence on fruit characteristics and drying time in convective drying of mango (Mangifera indica L.)
}

\author{
Amado, L. R. ${ }^{\text {a }}$ Silva, K. S. ${ }^{\text {b; Mauro, M. A. }}$ a* $^{\text {; }}$ \\ ${ }^{a}$ UNESP - São Paulo State University, Institute of Biosciences, Humanities and Exact Sciences \\ (IBILCE), São José do Rio Preto, SP, Brazil \\ b UEM - State University of Maringá, Umuarama, PR, Brazil \\ *Corresponding author: cidam@ibilce.unesp.br
}

\begin{abstract}
This study investigated the influence of the intermittent drying conditions on drying kinetics and on color and carotenoid retention of mangoes. The drying conditions were $95^{\circ} \mathrm{C}(40 \mathrm{~min})$ and $80^{\circ} \mathrm{C}$ (40 min) in the first stage combined with $70^{\circ} \mathrm{C}$ and $60^{\circ} \mathrm{C}$ in the second stage, and continuous drying $\left(70^{\circ} \mathrm{C}\right.$ and $60^{\circ} \mathrm{C}$ ) as control. Drying time was reduced by thermal intermittence and carotenoid retention was more affected by temperature than drying time. The results also highlighted the carotenoid sensitivity to $70^{\circ} \mathrm{C}$ temperature, showing the importance of limiting the temperature of the mango to $60^{\circ} \mathrm{C}$ during the two drying stages.
\end{abstract}

Keywords: Intermittent drying; thermal intermittence; carotenoid; color. 
Effects of thermal intermittence on fruit characteristics and drying time in convective drying of mango (Mangifera indica $L$.)

\section{Introduction}

Convective drying process provides many advantages over the shelf life extension of the food products. However, the drying of fruits in its most conventional way, can affect the nutritional quality of the dried products, due to prolonged exposure to oxygen and high temperatures. A possible way to reduce the negative effects of convective drying and still reduce energy consumption is to apply it under conditions of thermal intermittence, in which the conditions of time and temperature are modified during the same operation [1]. The drying of fruits with application of the thermal intermittence is based on their high moisture content at the beginning of the drying, whose surface temperature remains lower than the air because of water evaporation. This allows a higher temperature to be initially used and, consequently, reduces the drying time without causing significant damage to the product [2].

Regarding thermal intermittence, it is noted that this process is widely used in drying of grains and seeds, where tempering periods are used to reduce moisture gradients and avoid cracks $[3,4]$. However, there is a gap in the literature with regard to drying with thermal intermittence applied to high moisture food products. Among the existing works, most of them focus on the economy that the intermittence provides to the drying process, without evaluating the quality of the product, which can be considered a problem with respect to the nutritional aspects of food. Several authors have shown that intermittent drying conditions can lead to significant reductions in drying time and energy demand. For example, Váquiro et al. (2009) [5] dehydrated mango slices applying intermittence and obtained increased drying rates and reduced overall operating time, indicating a decrease in energy consumption. However, as foods with high water content are susceptible to many changes due to chemical and biochemical reactions, it is important to evaluate quality through parameters such as color and nutrient retention $[2,3]$.

The mango (Mangifera indica L.) is one of the most consumed fruits in the world, which is associated with their sensory properties and its high nutritional value, especially because of the antioxidant substances such as carotenoids, related to the prevention of several chronicdegenerative diseases and responsible for the mango color [6,7]. However, it is known that the mango is a seasonal fruit and presents considerable post-harvest losses, therefore, the use of preservation techniques like of convective drying is very important for these fruit, aiming to increase their shelf life.

The objective of this study was to evaluate the influence of the intermittent drying conditions on drying kinetics of mangoes as well as on their color and retention of carotenoids during process, aiming to reduce the time of operation and improve the sensory and nutritional quality of the dry mango. 


\section{Materials and Methods}

\subsection{Sample preparation}

The mangoes (Mangifera indica L.) cv. Palmer with an average soluble solids content of 11.0 $\pm 1.4{ }^{\circ}$ Brix and a moisture content between 81.8 and $86.0 \%$ on wet basis (w.b.) were acquired from nearby farms the region of São José do Rio Preto - São Paulo. In order to have a similar degree of maturity in all drying trials, the fruits were selected visually and based on manual contact. In each drying trial, nine mangoes $(4.5 \mathrm{~kg})$ randomly selected from a total of approximately 100 fruits were used. The mangoes were sanitized, sliced $(0.54 \pm 0.03 \mathrm{~cm}$ thick) with an electrical slicer (ECO, Brazil) and then, cut in circles (3.5 cm diameter) with a manual cutter.

\subsection{Drying trials}

The drying trials were performed using two identical fixed bed dryers with forced heated air convection according to Filippin (2018) [2]. A hot wire anemometer (Delta OHM, Italy) was used to determine the average velocity of the air in the drying chamber, which was approximately $1 \mathrm{~m} \cdot \mathrm{s}^{-1}$.

Six drying conditions were performed in duplicate, four of which were intermittent (I) in two stages, with the first stage at $95^{\circ} \mathrm{C}\left(\mathrm{H}=\right.$ higher temperature) or $80^{\circ} \mathrm{C}$ ( $\mathrm{L}=$ lower temperature), held for 40 minutes, and the second stage at $60^{\circ} \mathrm{C}(\mathrm{L})$ or $70^{\circ} \mathrm{C}(\mathrm{H})$. The other two conditions corresponded to continuous (C) dryings at $60^{\circ} \mathrm{C}$ and $70{ }^{\circ} \mathrm{C}$ (controls) (Table 1). The time range of the first stage was determined by monitoring the surface temperature of mango slices at the beginning of drying, considering as stop criterion the period that corresponds, approximately, to the time to reach the second stage temperature. All dryings were stopped when the samples reached moisture of approximately $8.7 \%( \pm 1.1)$. To establish the total drying time, the initial moisture of the samples was previously determined and the stopping point was based on the weight of the trays with the samples, which was previously calculated so that the samples reached the desired final moisture. The samples were weighed successively during drying using a semi-analytical balance (Gehaka, BK 4000, Brazil). The equilibrium moisture was determined in samples left in the dryer until reaching constant weight. Temperature and time values of the drying stages, as well as abbreviations used in the following tables of this work are shown in Table 1. 
Table 1. Temperature and time conditions for Intermittent and Continuous dryings

\begin{tabular}{|c|c|c|c|c|c|}
\hline \multirow[b]{2}{*}{ Trial } & \multirow[b]{2}{*}{ Abbreviation } & \multicolumn{2}{|c|}{ Temperature $\left({ }^{\circ} \mathrm{C}\right)$} & \multicolumn{2}{|c|}{ Time (min) } \\
\hline & & $\begin{array}{c}1^{\text {th }} \\
\text { Stage }\end{array}$ & $\begin{array}{c}2^{\text {nd }} \\
\text { Stage }\end{array}$ & $\begin{array}{c}1^{\text {th }} \\
\text { Stage }\end{array}$ & $2^{\text {nd }}$ Stage \\
\hline \multicolumn{6}{|l|}{ Intermittent drying } \\
\hline Intermittent $\left(80^{\circ} \mathrm{C} / 60^{\circ} \mathrm{C}\right)$ & I-LL & 80 & 60 & 40 & 230 \\
\hline Intermittent $\left(95^{\circ} \mathrm{C} / 60^{\circ} \mathrm{C}\right)$ & $\mathrm{I}-\mathrm{HL}$ & 95 & 60 & 40 & 200 \\
\hline Intermittent $\left(80^{\circ} \mathrm{C} / 70^{\circ} \mathrm{C}\right)$ & I-LH & 80 & 70 & 40 & 200 \\
\hline Intermittent $\left(95^{\circ} \mathrm{C} / 70^{\circ} \mathrm{C}\right)$ & I-HH & 95 & 70 & 40 & 170 \\
\hline \multicolumn{6}{|l|}{ Continuous drying } \\
\hline Continuous $\left(60^{\circ} \mathrm{C}\right)$ & C-L & \multicolumn{2}{|c|}{60} & \multicolumn{2}{|c|}{360} \\
\hline Continuous $\left(70^{\circ} \mathrm{C}\right)$ & $\mathrm{C}-\mathrm{H}$ & \multicolumn{2}{|c|}{70} & \multicolumn{2}{|c|}{300} \\
\hline
\end{tabular}

\subsection{Drying kinetics}

The effective diffusion coefficients of water were determined according to the Fick's second law, applied to an infinite flat plate. The analytical solution of the diffusion equation in its modified form, in terms of the mass fractions (dry basis, d.b.) and integrated on distance, is presented by Eq. (1) ${ }^{[8]}$ :

$$
X=\frac{\bar{X}_{w}(t)-X_{w}^{e q}}{X_{w}^{0}-X_{w}^{e q}}=\frac{8}{\pi^{2}} \sum_{n=1}^{\infty} \frac{1}{(2 n-1)^{2}} \exp \left[-(2 n-1)^{2} \frac{\pi^{2} \mathrm{D}_{\mathrm{eff}} t}{e^{2}}\right]
$$

where $\mathrm{X}$ is the residual moisture content, dimensionless; $\bar{X}_{w}$ represents the mean mass fraction of the water on a dry weight basis $\left(\mathrm{kg} \cdot \mathrm{kg}^{-1}\right)$ at the drying time $t(\mathrm{~s}) ; X_{w}^{0}$ and $X_{w}^{e q}$ represents the water mass fraction on a dry weight basis $\left(\mathrm{kg} \cdot \mathrm{kg}^{-1}\right)$ at the initial moment $(t=$ 0 ) and at equilibrium (eq); $\mathrm{D}_{\text {eff }}$ represents the effective diffusion coefficient $\left(\mathrm{m}^{2} \cdot \mathrm{s}^{-1}\right)$; $e$ is the thickness of the samples (m); $n$ is the number of terms in the series.

The shrinkage of the sample was considered by applying a simplified procedure that incorporates the volumetric contraction in an approximate way in Eq. (1) through the characteristic dimension ( $e$ ) as a function of the water content. From the fruit volume variation during drying, the final thicknesses of the samples were estimated considering that shrinkage occurred in the same proportion, in each dimension of the solid [9], as follows:

$$
\frac{e}{e_{0}}=\left(\frac{V}{V_{0}}\right)^{1 / 3}
$$

where $e(\mathrm{~m})$ is the thickness at time $t(\mathrm{~s})$ and $V\left(\mathrm{~m}^{3}\right)$ is the volume at time $t(\mathrm{~s})$; sub index 0 represents initial time $(t=0)$. 
The volumes were calculated based on the thickness and diameter measurements performed on the mango samples, before and after each drying experiment. The thickness was then described as a linear function of the water content, on a dry basis, and incorporated into the Eq (1), to fit the model to the experimental results.

Water diffusion coefficients were determined according to Eq. (1), for each stage, separately, as described by Filippin (2018) [2]. The fitting method used in the estimation of the nonlinear parameters was based on the Levenberg-Marquardt algorithm [10].

\subsection{Analytical methods}

Thickness, total solids, total carotenoid, and color parameters were analyzed before and after drying, besides diameter after drying. The thickness was measured using a digital micrometer (MDC-25SB, Mitutoyo, Japan) and the diameter using a pachymeter (Stainless Hardened, 806178, USA), both used to calculate the volumetric variation of the samples during drying. Total solids content was determined gravimetrically, in a vacuum oven (TE-395, Tecnal, Brazil) at $60{ }^{\circ} \mathrm{C}$ until constant weight. Total carotenoid content was determined by spectrophotometric reading (Thermo Scientific, GENESYS 10S UV-VIS, EUA) (absorbance at $450 \mathrm{~nm}$ ) as $\beta$-carotene, according to Rodriguez-Amaya and Kimura (2004) [11] and its retention during drying was analyzed as Eq. (3):

$$
\operatorname{Ret}(\%)=100 \frac{(\mu \mathrm{g} \text { carotenoid } / \mathrm{kg} \text { dried mango }) \times \mathrm{kg} \text { dried mango after drying }}{(\mu \mathrm{g} \text { carotenoid } / \mathrm{kg} \text { raw mango }) \times \mathrm{kg} \text { raw mango before drying }}
$$

Color parameters based on the CIELAB system $\left(\mathrm{L}^{*}, \mathrm{a}^{*}, \mathrm{~b}^{*}\right)$ were obtained using a Colorflex spectrophotometer (HunterLab, Resto, USA). All color parameters ( $\mathrm{P}^{*}$ ) measured after drying $(t)$ were evaluated in relation to their corresponding values before drying $(t=0)$. The process conditions that presented the ratios $\mathrm{P}^{*}(\mathrm{t}) / \mathrm{P} *(\mathrm{t}=0)$ tending to unity were considered effective in reducing the color changes.

\subsection{Statistical methods}

The fitting efficiency of the diffusion coefficient was evaluated by the correlation coefficient $R^{2}$ and the mean relative error ( $P \%$ ), according to Eq. (4):

$$
P(\%)=\frac{100}{n} \sum_{1}^{n} \frac{\left|y^{\exp }-y^{c a l}\right|}{y^{\exp }}
$$

where $y^{\text {calc }}$ represents the water content on a dry basis, $y^{\exp }$ is the experimental value, and $n$ is the number of observations or residuals. 
Effects of thermal intermittence on fruit characteristics and drying time in convective drying of mango (Mangifera indica $L$.)

\section{Results and discussion}

\subsection{Drying kinetics}

Table 2 shows the values for diffusivity ( $\left.\mathrm{D}_{\text {eff }}\right)$ and the determination coefficients $\left(\mathrm{R}^{2}\right)$ and relative errors $(\mathrm{P}(\%))$ for the drying trials. In relation to the diffusion coefficients, in general, the higher temperatures lead to higher diffusion coefficients.

Evaluating the fit of the model, high P (\%) values were observed for the second stage of intermittent drying and for continuous drying (above 10\%), as the error measurement makes the relative deviations very high when the water content is very small. However, the coefficients of variation $\left(\mathrm{R}^{2}\right)$ were all higher than 0.986 , indicating satisfactory fit.

From the determination of the diffusivity, the moisture (dry basis) graphs were plotted as a function of time (Fig. 1) of the predicted values, which were compared with the experimental data. From the graphs, it can be observed that the predicted values are close to those observed for both intermittent drying stages and for continuous drying (Fig. 1).

Table 2. Effective diffusion coefficients $\left(D_{\text {eff }} \times 10^{10}\left(\mathrm{~m}^{2} \cdot \mathrm{s}^{-1}\right)\right)$ for the Intermittent $\left(1^{\text {th }}\right.$ and $2^{\text {nd }}$ Stage) and Continuous dryings, number of repetitions (Rep), total drying time, $\mathbf{R}^{2}$ and $\mathbf{P}(\%)$

\begin{tabular}{|c|c|c|c|c|c|c|c|c|c|c|}
\hline \multirow{2}{*}{$\begin{array}{l}\text { Trial } \\
\text { Rep }\end{array}$} & & \multirow[b]{2}{*}{$\begin{array}{c}\text { Total } \\
\text { time } \\
(\mathrm{min})\end{array}$} & \multicolumn{4}{|c|}{$1^{\text {th }}$ Stage } & \multicolumn{4}{|c|}{$2^{\text {nd }}$ Stage } \\
\hline & & & $\mathbf{D}_{\text {eff }}$ & $\mathbf{R}^{2}$ & $\begin{array}{c}\mathbf{P} \\
(\%)\end{array}$ & Mean $\mathbf{D}_{\text {eff }}$ & $\mathbf{D}_{\text {eff }}$ & $\mathbf{R}^{2}$ & $\begin{array}{c}\mathbf{P} \\
(\%)\end{array}$ & Mean $D_{\text {eff }}$ \\
\hline \multicolumn{11}{|c|}{ Intermittent drying } \\
\hline I-LL & $\begin{array}{l}1 \\
2\end{array}$ & 270 & $\begin{array}{l}4.08 \\
3.69\end{array}$ & $\begin{array}{l}0.997 \\
0.997\end{array}$ & $\begin{array}{l}1.0 \\
1.2\end{array}$ & $3.88 \pm 0.27$ & $\begin{array}{l}2.35 \\
1.84\end{array}$ & $\begin{array}{l}0.992 \\
0.998\end{array}$ & $\begin{array}{l}14.0 \\
14.0\end{array}$ & $2.10 \pm 0.36$ \\
\hline I-HL & $\begin{array}{l}1 \\
2\end{array}$ & 240 & $\begin{array}{l}4.54 \\
5.28\end{array}$ & $\begin{array}{l}0.997 \\
0.999\end{array}$ & $\begin{array}{l}1.7 \\
0.8\end{array}$ & $4.91 \pm 0.52$ & $\begin{array}{l}2.42 \\
2.33\end{array}$ & $\begin{array}{l}0.992 \\
0.987\end{array}$ & $\begin{array}{l}12.9 \\
13.4\end{array}$ & $2.38 \pm 0.06$ \\
\hline I-LH & $\begin{array}{l}1 \\
2\end{array}$ & 240 & $\begin{array}{l}3.91 \\
3.65\end{array}$ & $\begin{array}{l}0.995 \\
0.997\end{array}$ & $\begin{array}{l}1.4 \\
0.9\end{array}$ & $3.78 \pm 0.19$ & $\begin{array}{l}2.93 \\
2.78\end{array}$ & $\begin{array}{l}0.991 \\
0.992\end{array}$ & $\begin{array}{l}16.9 \\
25.7\end{array}$ & $2.86 \pm 0.11$ \\
\hline $\begin{array}{c}\mathrm{I}- \\
\mathrm{HH}\end{array}$ & $\begin{array}{l}1 \\
2\end{array}$ & 210 & $\begin{array}{l}5.61 \\
4.72\end{array}$ & $\begin{array}{l}0.998 \\
0.997\end{array}$ & $\begin{array}{l}1.2 \\
1.2\end{array}$ & $5.16 \pm 0.63$ & $\begin{array}{l}3.28 \\
2.69\end{array}$ & $\begin{array}{l}0.986 \\
0.986\end{array}$ & $\begin{array}{l}29.2 \\
23.1\end{array}$ & $2.99 \pm 0.42$ \\
\hline \multicolumn{11}{|c|}{ Continuous drying } \\
\hline C-L & $\begin{array}{l}1 \\
2\end{array}$ & 360 & - & - & - & - & $\begin{array}{l}2.36 \\
1.97\end{array}$ & $\begin{array}{l}0.998 \\
0.997\end{array}$ & $\begin{array}{l}17.8 \\
13.9\end{array}$ & $2.17 \pm 0.28$ \\
\hline $\mathrm{C}-\mathrm{H}$ & $\begin{array}{l}1 \\
2\end{array}$ & 300 & - & - & - & - & $\begin{array}{l}2.89 \\
2.76\end{array}$ & $\begin{array}{l}0.998 \\
0.997\end{array}$ & $\begin{array}{l}14.3 \\
13.3\end{array}$ & $2.83 \pm 0.09$ \\
\hline
\end{tabular}



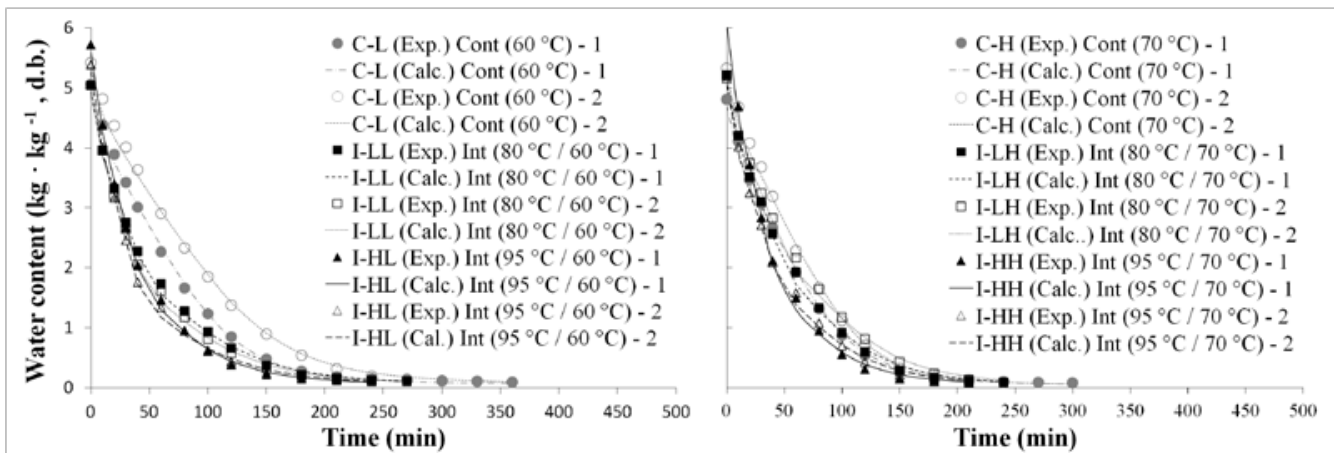

Fig. 1 Experimental (Exp.) and predicted (Calc.) values for the water content (d.b.) as a function of drying time, for intermittent (I-) and continuous (C-) trials.

\subsection{Color and carotenoid retention}

The carotenoid retention and normalized color parameter values of the dried mango are presented in Table 3. Drying at $95{ }^{\circ} \mathrm{C} / 60{ }^{\circ} \mathrm{C}$ (I-HL) was the condition that provided the best preservation of carotenoid, followed by $80{ }^{\circ} \mathrm{C} / 60{ }^{\circ} \mathrm{C}$ (I-LL), and also the continuous drying at $60^{\circ} \mathrm{C}(\mathrm{C}-\mathrm{L})$, which highlighted the carotenoid sensitivity to $70^{\circ} \mathrm{C}$.

The color parameters did not show relevant changes in the different operating conditions. However, it was possible to verify that the greatest variations in the normalized a* parameters were related to the continuous dryings ( $\mathrm{C}-\mathrm{L}$ and $\mathrm{C}-\mathrm{H})$, and also with those intermittent dryings in which the second stage temperature was $70{ }^{\circ} \mathrm{C}$ (I-LH and $\left.\mathrm{I}-\mathrm{HH}\right)$. This suggests therefore, that long drying times and $70^{\circ} \mathrm{C}$ temperature could affect them more intensively.

Table 3. Carotenoid retention Ret $(\%)$ and normalized color parameters $\mathbf{P}^{*}(\mathrm{t}) / \mathrm{P}^{*}(\mathrm{t}=\mathbf{0})$ for each repetition (Rep) of intermittent (I-) and continuous (C-) trials.

\begin{tabular}{ccccccc}
\hline Trial & Rep. & $\begin{array}{c}\text { Ret } \\
\mathbf{( \% )}\end{array}$ & $\begin{array}{c}\text { Mean Ret } \\
\mathbf{( \% )}\end{array}$ & $\mathbf{L}^{*}$ dried/L*fresh & $\mathbf{a}^{*}$ dried/ $\mathbf{a}^{*}$ fresh & $\mathbf{b}^{*}$ dried/ $\mathbf{b}^{*}$ fresh \\
\hline I-LL & 1 & 70.27 & $67.86 \pm 3.40$ & $0.95 \pm 0.03$ & $1.21 \pm 0.33$ & $0.91 \pm 0.06$ \\
& 2 & 65.46 & & & & \\
I-HL & 1 & 67.08 & $68.22 \pm 1.61$ & $1.03 \pm 0.03$ & $1.13 \pm 0.01$ & $1.02 \pm 0.00$ \\
& 2 & 69.36 & & & & \\
I-LH & 1 & 57.09 & $58.59 \pm 2.12$ & $0.95 \pm 0.04$ & $1.55 \pm 0.48$ & $0.98 \pm 0.03$ \\
& 2 & 60.09 & & & & \\
I-HH & 1 & 54.65 & $54.73 \pm 0.11$ & $0.96 \pm 0.06$ & $1.54 \pm 0.64$ & $0.93 \pm 0.05$ \\
& 2 & 54.81 & & & & \\
C-L & 1 & 67.71 & $64.42 \pm 4.65$ & $0.92 \pm 0.11$ & $1.70 \pm 0.32$ & $0.95 \pm 0.10$ \\
& 2 & 61.13 & & & & \\
C-H & 1 & 59.51 & $60.77 \pm 1.78$ & $0.93 \pm 0.05$ & $1.90 \pm 1.04$ & $1.05 \pm 0.25$ \\
\hline
\end{tabular}


Effects of thermal intermittence on fruit characteristics and drying time in convective drying of mango (Mangifera indica $L$.)

\section{Conclusions}

Despite the drying conditions causing only small changes in the color parameters, they seemed to be more affected by the long drying times. More noticeably, the total drying time was reduced by thermal intermittence, by the increase of the first stage temperature of all intermittent dryings, and also when the second stage was $70{ }^{\circ} \mathrm{C}$. Temperature affected carotenoid retention more than drying time, and their sensitivity to $70{ }^{\circ} \mathrm{C}$ confirmed the importance of limiting the sample temperature to $60^{\circ} \mathrm{C}$ during the two drying stages.

Acknowledgment: We would like to thank FAPESP for their scholarship (Proc. 2015/18638-7) and financial support (Proc. 2014/11514-8) and CNPq.

\section{References}

[1] Kumar, C.; Karin, M. A.; Joardder, M. Intermittent Drying of Food Products: A Critical Review. Journal of Food Engineering, 2014, 121, 48-57.

[2] Filippin, A. P.; Molina Filho, L.; Fadel, V.; Mauro, M. A. Thermal intermittent drying of apples and its effects on energy consumption. Drying Technology, 2018. https://doi.org/10.1080/07373937.2017.1421549

[3] Kowalski, S. J.; Szadzinska, J.; Lechtanska. Non-stationary drying of carrot: Effect on product quality. Journal of Food Engineering, 2013, 118, 393-399.

[4] Shei, H.J.; Chen, Y.L. Computer simulation on intermittent drying of rough rice. Drying Technology. 2002, 20, 615-636.

[5] Vaquiro, H. A.; Clemente, G.; Garcia-Perez, J. V.; Mulet, A., Bon, J. Enthalpy-Driven Optimization of Intermittent Drying of Mangifera indica L. Chemical Engineering Research and Design. 2009, 87(7), 885-898.

[6] Dorta, E.; González, M.; Lobo, M. G.; Sánchez-Moreno, C.; Ancos, B. Screening of phenolic compounds in by-product extracts from mangoes (Mangifera indica L.) by HPLC-ESI-QTOF-MS and multivariate analysis for use as a food ingredient. Food Research International. 2014, 57, 51-60.

[7] Faria, A. F.; Hasegawa, P. N.; Chagas, E. A.; Pio, R.; Purgatto, E.; Mercadante, A. Z. Cultivar influence on carotenoid composition of loquats from Brazil. Journal of Food Composition and Analysis. 2009, 22, 196-203.

[8] Crank, J. The mathematics of Diffusion. 2nd ed . Oxford: Claredon Press, 1975.

[9] Molina Filho, L.; Frascareli, E. C.; Mauro, M. A. Effect of an Edible Pectin Coating and Blanching Pretreatments on the Air-Drying Kinetics of Pumpkin (Cucurbita moschata). Food and Bioprocess Technology. 2016, 9(5), 859-871.

[10] Marquart, D. W. An Algorithm for Least-Squares Estimation of Nonlinear Parameters. Journal of the Society for Industrial and Applied Mathematics. 1963, 11(2), 431-441.

[11] Rodriguez-Amaya, D. B.; Kimura, M. Screening method for sweetpotato and cassava. In: HarvestPlus Handbook for Carotenoid Analysis, International Food Policy Research Institute (IFPRI), Washington, D. C., 2004, 58. 